\title{
3D GEO-INFORMATION IN URBAN CLIMATE STUDIES
}

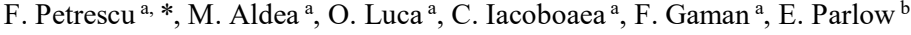 \\ ${ }^{a}$ Urban Engineering and Regional Development Department, Technical University of Civil Engineering Bucharest, Bd. Lacul Tei \\ 124, sector 2, 020396 Bucharest, Romania - (florianp, imihaela, oana, cristinai, gflorin)@utcb.ro \\ ${ }^{\mathrm{b}}$ Meteorology, Climatology and Remote Sensing (MCR Lab), Department of Environmental Sciences, University of Basel, \\ Klingelbergstr. 27, CH-4056, Basel, Switzerland - eberhard.parlow@unibas.ch
}

KEY WORDS: 3D geo-information, Urban climate, Urban planning, Urban climate characteristics, Numerical models

\begin{abstract}
:
3D geo-information is essential for urban climate studies. It is obvious that both natural environment and built-up environment play the fundamental role in defining the climatic conditions for urban areas, which affect the quality of human life and human comfort. The paper presents the main categories of 3D geo-information used in urban climate studies and roles in creating and operating the numerical models specially designed to simulate urban planning scenarios and improvement of the urban climate situation.
\end{abstract}

\section{INTRODUCTION}

Urban climate is quite different from that of rural areas. A complex heterogeneous urban morphology and sealed surfaces with different thermal inertia contribute to varying urban microclimates with different impacts on the bioclimatic conditions for the inhabitants.

The methodologies used are in some studies surface measurements of radiation, heat and $\mathrm{CO}_{2}$ fluxes by eddy covariance measurements and gas analysers, others prefer a remote sensing approach using space-borne or air-borne imagery, and finally in many applications oriented studies numerical models are integrated to compute various possible scenarios of the urban design and architecture. The remote sensing approach to study the urban climate is mostly done by using thermal infrared data. Urban surfaces often show higher temperatures compared to their rural surroundings.

The determination of urban surface radiation balance or the heat fluxes encounters several difficulties because of the inhomogeneous surface in urban areas. The energy balance and therefore the storage flux are influenced by radiation balance and the surface radiation fluxes of urban canyons. Furthermore the radiation budget cannot be modelled without taking into account the complex 3D-geometry of roofs, walls and buildings. The parameterisation of the geometry of urban canyons remains therefore a crucial problem to this field of research, especially when working with satellite data whose spatial resolution stays below the size of buildings. A very detailed investigation on the influence of the 3D-geometry of urban structures on spatially distributed radiation fluxes was published by (Frey \& Parlow, 2008).

The paper addresses the following problem: starting from the particular urban climate characteristics of a city and taking into account the 3D model of the city, build answers to the main questions related to the urban climate by simulating scenarios

* Corresponding author for parameters such as the Predicted Mean Vote (PMV) index, the Sky-View Factor (SVF), temperature, the main wind flow, albedos, and humidity and $\mathrm{CO}_{2}$ density.

Section 2 presents the main urban climatic characteristics, while section 3 deals with the integration of numerical models especially designed to simulate urban planning scenarios for the improvement of the urban climate situation. The model used is ENVI-met, which is widely applied in other countries.

The results obtained by running the ENVI-met model are presented in the $4^{\text {th }}$ section, which is dedicated to the Bucharest study case.

\section{URBAN CLIMATIC CHARACTERISTICS}

The main factors influencing the urban microclimate are usually contributing to the manifestation of the urban heat island effect, the air masses movement at the pedestrian-level and the quality of air. These factors are generally: the surface geometry, the thermal properties of the urban materials, the surface imperviousness, the anthropogenic heat and the air pollution.

The climatic conditions for urban areas which affect the quality of human life and human comfort are mostly related with: temperature, wind, air composition, humidity.

Temperatures in the city are generally higher than in their rural vicinity. Walls and roofs of the buildings and asphalt pavements have higher radiation surface than open lands yielding higher amount of solar energy absorbed. These materials have also a greater heat capacity which means that urban materials absorb and retain more solar radiation than do rural soils and vegetation.

Wind is very important for the urban microclimate and usually, due to the higher temperatures in the cities producing a low pressure region in the atmosphere, have a continuous flow from rural to urban areas but also the wind speed is greatly reduced due to the the increased friction created by a rough urban 
surface. Wind is affected by the $3 \mathrm{D}$ configuration of the buildings as the wind may be channeled around buildings, between buildings or along avenues causing accelerated wind speeds at pedestrian level and giving rise to pedestrian discomfort. Wind can also be influenced by high-rise buildings which form a configuration that blocks the wind, these sheltered areas experiencing insufficient air circulation and diminished natural ventilation.

Air composition is changed for the worse by the particles and greenhouse gases in the cities atmosphere are in much higher concentrations, affect the human health and they pollute the urban air. Also, these pollutants hinder the solar radiation which arrives in an urban area.

Humidity is generally influenced by the evaporation of the water in unsealed land cover resulting in more energy is put into sensible heat than into latent heat (Santamouris, 2001). Green vegetation can also decrease air temperature by transpiration of an important quantity of water. (Matczak, McEvoy, Banaszak, \& Chorynski, 2005).

\section{FROM MEASUREMENTS TO MODEL}

All the factors mentioned in the previous section which influence the urban microclimate can be included into a 3D city model which can integrate all the characteristics of the surface geometry by the 3D modelling of the buildings and of the city trees, as for the thermal properties of the urban materials, the surface imperviousness, the anthropogenic heat and the $\mathrm{CO}_{2}$ levels, they can be attached to the land cover type.

The computational fluid dynamics (CFD) has become more intensively used in order to perform design simulations for quantitative analyses of the urban effects on climate and in preevaluation of certain urban developments in urban planning (Yang, Wen, Cheng, \& Juan, 2015). Thus, (Bruse, 2004) lays out the approach for the 3D non-hydrostatic urban-climate model, ENVI-met, in which the main prognostic variables in the atmospheric model are: the main wind flow, temperature, humidity and turbulence.

The ENVI-met microclimate CFD model has been used to simulate interactions between urban surfaces, vegetation and the atmosphere in many studies (Kim, An, Eum, \& Woo, 2016).

The input parameters of an ENVI-met simulation are mainly represented by the 3D structure of the urban surfaces and vegetation, together with their physical properties, followed by the measured values for the initial or forced meteorological conditions. It should be pointed out that ENVI-met produces a numerical simulation constructed on the $3 \mathrm{D}$ representation of the city volumes and that the measured terms are set globally for the entire area. It is expected that the results are representative for the 3D city model integrated response of the buildings, roads, vegetation etc. Other than the measurements, which set the global model boundary condition, the measurements are best used for validation purposes, as long as the measurement points are the same as the receptors selected for ENVI-met simulations. It should be also pointed out that ENVI-met cannot be used for the assessment of anthropogenic heat emissions (Berardi \& Wang, 2016).

The results from the CFD simulations in models such as ENVImet can be considered at a micro scale which usually to covers a horizontal length ranging from 100 to more than $1000 \mathrm{~m}$, such that they can account for the effect of each type of land cover within the city such as streets, buildings, parks, districts etc. There are certain possibilities to mitigate the negative effects produced by some of these structures over the urban climate by the suitable placement of the vegetation cover and of the buildings combined with the use of proper building materials etc.

More important is that this cannot be done without a 3D city model based on data gathered with Remote Sensing technologies and Geographic Information Systems (GIS). With the use of these tools and techniques it is possible to analyse ventilation pathways and the urban heat island effect by mapping out the factors indicating the relationship between urban geometry, land cover and urban wind ventilation and temperature with such indicators as the Sky View Factor, Height-to-Width ratios $(\mathrm{H} / \mathrm{W})$, etc. retrieved from the 3D model.

\section{BUCHAREST CASE STUDY}

In order to assess the climate conditions for the Romanian capital city such 3D city models were developed in the "Urban Climate Study of Bucharest/Romania", a project with bilateral founding by the Swiss National Science Foundation and Romanian Research Agency (UEFISCDI) within the RomanianSwiss Research Programme by both the Swiss (for the city center) (Andreas, Vogt, Parlow, \& Petrescu, 2015) and the Romanian partners. The Romanian 3D city model was developed for a study area which was selected on the northern edge of the Bucharest city, in the vicinity of the Technical University of Civil Engineering campus where the observation site is located. In this area there are several of the University's buildings of various heights. The "Tei" district selected for modelling extends over an $825 \times 845$ meters area, and comprises a mixture of concrete blocks of flats and one-floor buildings. Land cover is also mixed, consisting in residential built-up areas, asphalt covered streets and sidewalks, a park and a lake. A measurement tower is installed on the University's highest building which is a ten story dorm (approximately $32 \mathrm{~m}$ from street level). The tower is a $12 \mathrm{~m}$ flux tower on top of the building which covers an area with a radius of several hundred meters and was installed as part of and performed micrometeorological measurements. The instruments mounted at the site provide different sets of urban micrometeorological measurements and outputs. An IRGASON Integrated $\mathrm{CO}_{2} / \mathrm{H}_{2} \mathrm{O}$ Open-Path Gas Analyser and 3D Sonic Anemometer which measures and outputs orthogonal wind components, sonic temperature, densities of carbon dioxide and water vapour, air temperature and air pressure. A CNR4 Net Radiometer measures the individual components of the radiation balance by outputting upward and downward short-wave solar radiation and long-wave far infrared radiation values. The general meteorological conditions are measured by a Vaisala WXT 520 Weather Transmitter which outputs air temperature, relative humidity, air pressure, wind speed, wind direction and precipitation.

The local meteorological data for Bucharest introduced in the model as inputs for the meteorological conditions are based on the average annual local atmospheric wind conditions, which rely on historical meteorological data provided by the Romanian Meteorological Service and also based on the local measurements of the flux tower placed on the University Dorm building. 
The CFD simulation of the 3D Bucharest model was conducted with both versions of the ENVI-met model that is 3.1 (Wicki, et al., 2015) and 4, for various dates. For example, one of the selected date was the $29^{\text {th }}$ of July, which was one of the hottest days in 2015. The main variables estimated in the ENVI-met model and presented next are: the Predicted Mean Vote (PMV) index, the Sky-View Factor (SVF), temperature, the main wind flow, albedos, and humidity and $\mathrm{CO}_{2}$ density. It should be mentioned here that the Predicted Mean Vote is a thermal comfort index (Fanger, 1982) which relates the energy balance of the human body with the human thermal impression by an empirical function and it ranges from -4 (very cold) to +4 (very hot) where 0 is the thermal neutral (comfort) value. Our ENVImet simulation produced estimation values which seem to be related to the shadowed areas and high vegetation (trees) as it is shown in Figure 1.

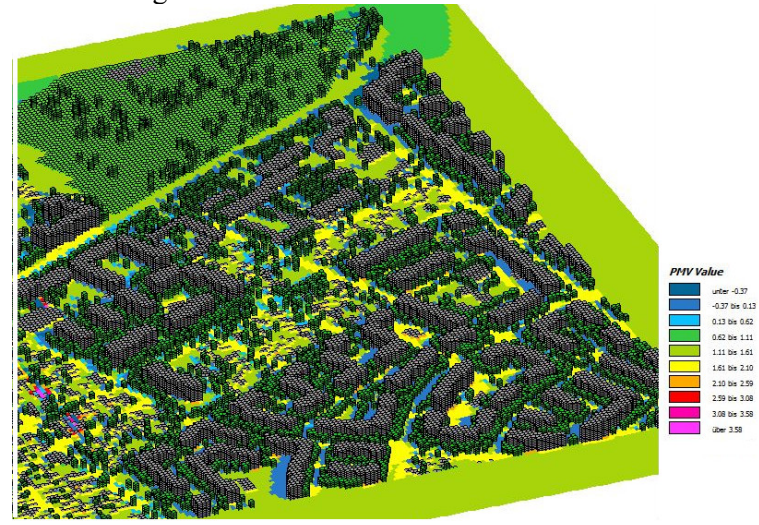

Figure 1. The simulated index of Predicted Mean Vote related to the shadowed areas and high vegetation (trees)

The sky view factor (SVF) was introduced by (Watson \& Johnson, 1987) and is calculated as the fraction of sky visible when viewed from the ground upward. SVF is dimensionless and ranges from 0 (sky is not visible) to 1 (sky is completely visible). The ENVI-met simulation produced the SVF presented in Figure 2, and which is an important parameter which can be used in the consideration of the possibility of the development of the UHI effect (Oke, 1987).

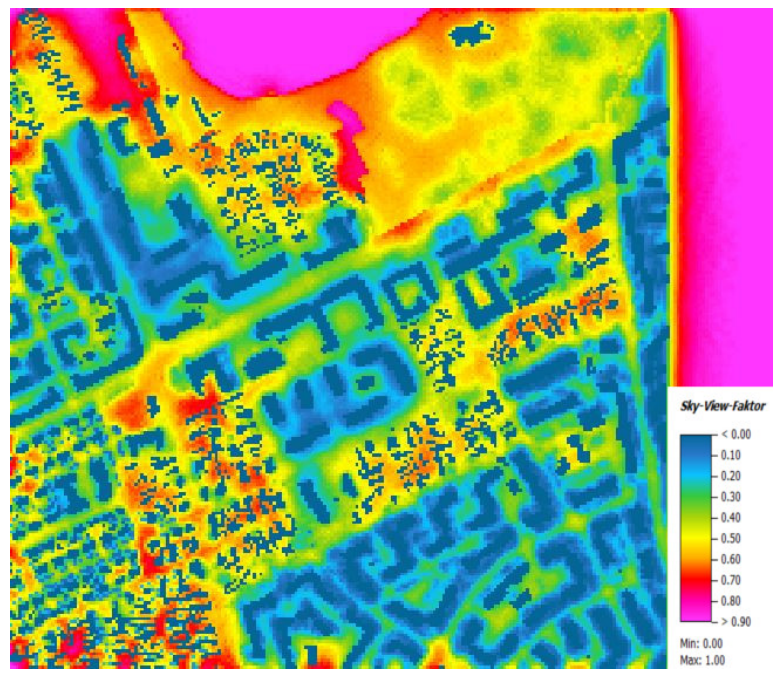

Figure 2. The simulated Sky View Factor pointing out areas with the sky almost not visible.
The simulated air temperatures are presented in Figure 3 sectioned by a plane at the elevation $\mathrm{z}=1.4 \mathrm{~m}$ which is usually affecting human size and Figure 4 which distinguishes the warmer urban canyons in the entire district, produced as a consequence of the $0.2 \mathrm{SVF}$ and albedos.

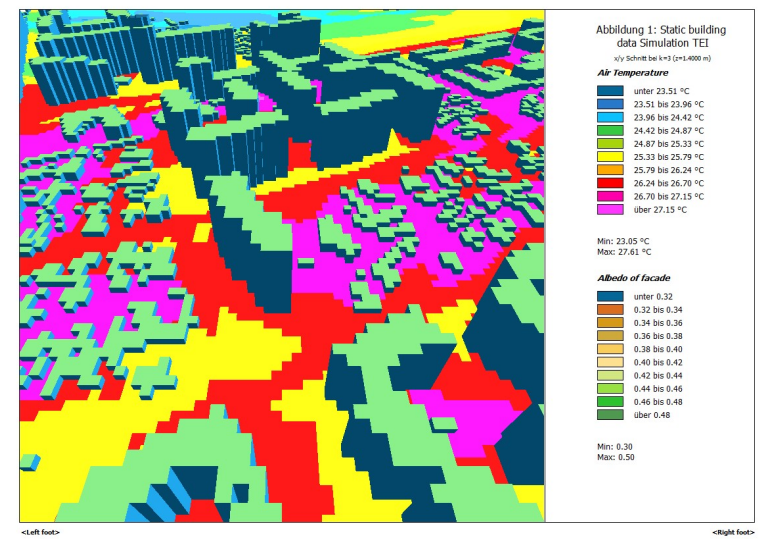

Figure 3. The 3D Air temperatures at the elevation $\mathrm{z}=1.4 \mathrm{~m}$

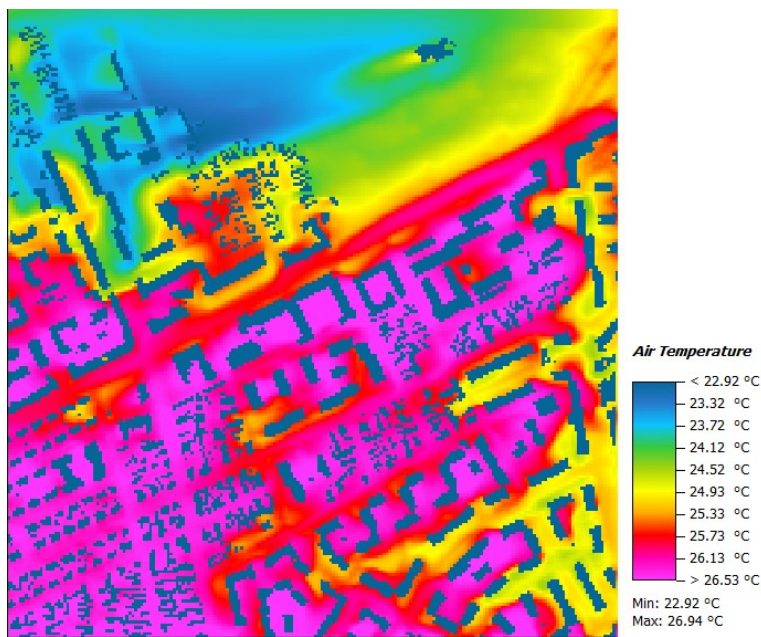

Figure 4 . The 2D Air temperatures and the estimated urban canyons

The wind flow was also estimated for the entire district and presented in Figure 5 in a 3D setting presenting the speeds attained around the area of our measurement flux tower, in Figure 6 in a 2D layout showing the direction vectors together with the vertical wind profiles in the $\mathrm{x}$ direction (Figure 7). 


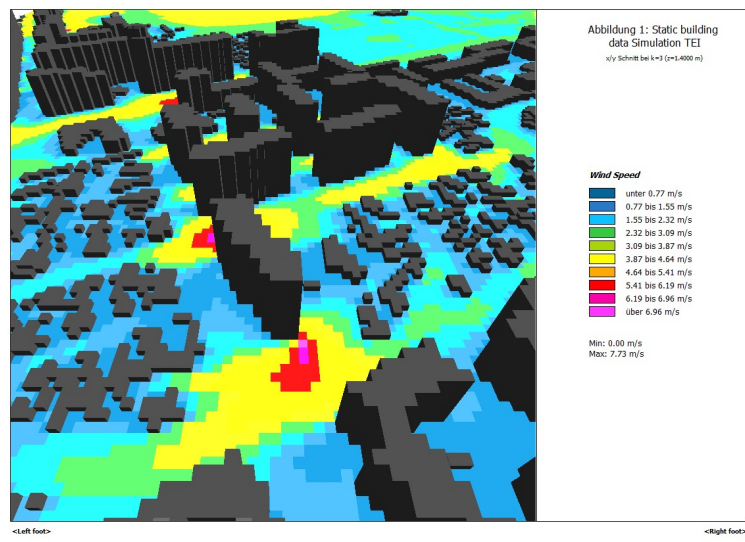

Figure 5. The 3D layout of the buildings and wind speeds around them

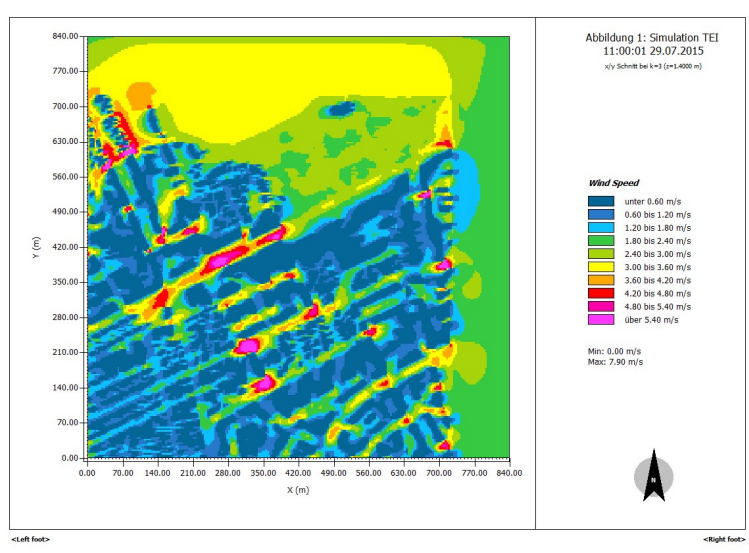

Figure 6 . The wind speeds attained in the entire district

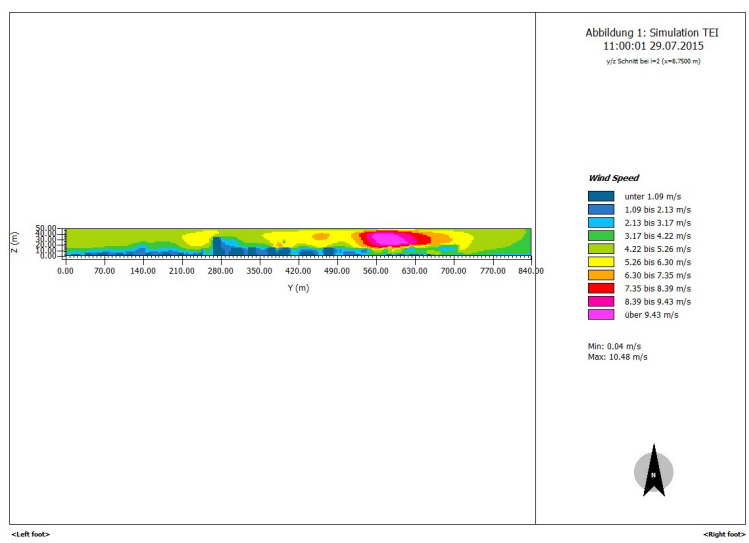

Figure 7. The wind profile in the $y-z$ plane

The $\mathrm{CO}_{2}$ estimated values are closely related with the vegetation cover as it is shown in Figure 8, with the vegetation and the sealing level of the land cover being also related the humidity in Figure 9.

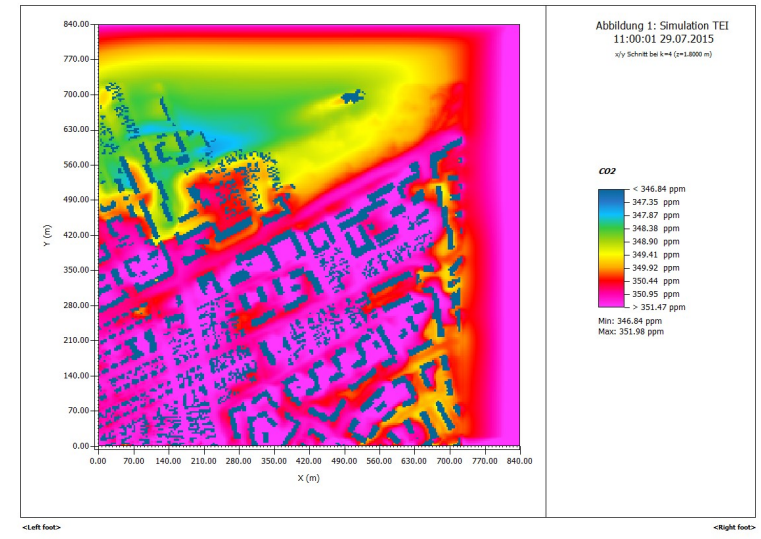

Figure 8. The $\mathrm{CO}_{2}$ estimated values

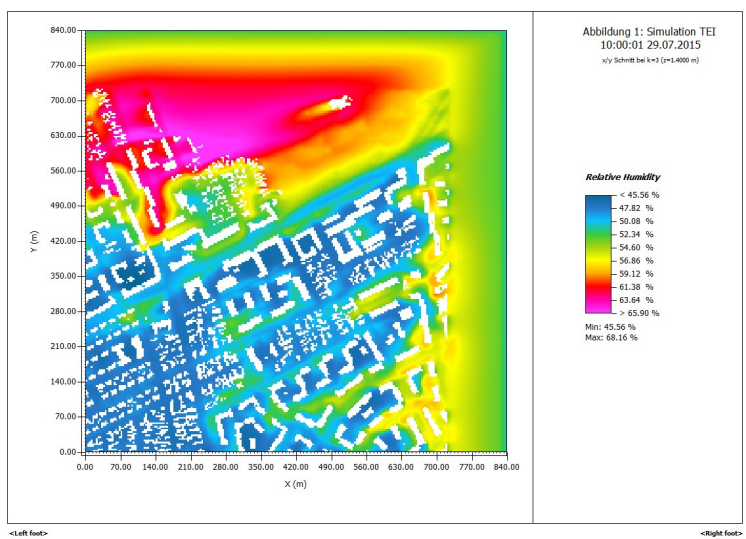

Figure 9 . The relative humidity estimated values

\section{CONCLUSIONS}

The aim of this paper was to run ENVI-met numerical model in order to understand the climatic effect of the 3D city model and land cover types over which kind of estimates and simulations are possible for past or future situations in order to determine the urban climate conditions. The firs type of analysis which was conducted referred to the evaluation of the present state of the urban microclimate, the estimation of influencing factors over certain outputs and correlations between different parameters can be calculated, and the best areas suitable for human comfort can be assessed.

The second type of analysis that can be done so far concerns the various comparisons between the values of different parameters measured by the instruments on the flux tower and the microclimate modeling results from ENVI-met.

The third type of analysis consists in estimating the urban climate before and after the new configurations of the site are simulated and compared (like newly proposed constructions). Particular comparisons can be done regarding to the influence of the vegetation and to the use of high albedo materials.

To conclude, for a more accurate assessment of the microclimatic conditions at the local level of the selected urban area, the 3D information is essential for obtaining a reliable climate model. Also, the 3D city model can be successfully used 
as input for the 3D parameters in an advanced 3D-4D (including time series) environmental model like ENVI-met. Our work proved that, in order to assess and quantify the small to larger-scale climatic impacts, numerical models which have the capacity to simulate the future behavior of the climatic parameters and of human comfort should become an integrated part of the information system of any city and a base for urban planning decision.

\section{ACKNOWLEDGEMENTS}

This work was supported by the Swiss Enlargement Contribution in the framework of the Romanian-Swiss Research Programme, under project number IZERZ0_142160 entitled Urban Climate Study of Bucharest.

\section{REFERENCES}

Berardi, U., \& Wang, Y., 2016. The Effect of a Denser City over the Urban Microclimate: The Case of Toronto. Sustainability 2016, 8(8), 822.

Bruse, M., 2004. ENVI-met 3.0: updated model overview. Retrieved from www.envi-met.com (29 Jul. 2016).

Fanger, P. O., 1982. Thermal Comfort. Analysis and Application in Environment Engineering, McGraw Hill Book Company, New York.

Frey, C. M. \& E. Parlow, 2008. Geometry effect on the estimation of band reflectance in an urban area. Theoretical and Applied Climatology, 96, p. 395-406.

Kim, Y., An, S., Eum, J., \& Woo, J., 2016. Analysis of Thermal Environment over a Small-Scale Landscape in a Densely BuiltUp Asian Megacity. Sustainability, 8(4), 358.

Matczak, P., McEvoy, D., Banaszak, I., \& Chorynski, A., 2005. Green infrastructure in urban areas. London: MEA, 2005 MEA, Ecosystems and Human Well-Being, Synthesis, Island Press.

Oke, T. R. 1987. Boundary Layer Climates. $2^{\text {nd }}$, Methuen and Co, New York.

Santamouris, M., 2001. On the built environment-the urban influence. In V. A. D.N. Asimakopoulos, Energy and Climate in the U rban Built Environment. New York: Routledge Taylor \& Francis Group.

Yang, A., Wen, C., Cheng, C., \& Juan, Y., 2015. CFD Simulations to Study the Cooling Effects of Different Greening Modifications. YANG, An-Shik, et al. CFD Simulations to Study the Cooling Effects of Different Greening Modifications. World Academy of Science, Engineering and Technology, International Journal of Environmental, Chemical, Ecological, Geological and Geophysical Engineer, 9(7), 808-814.

Watson, I.D., and G.T. Johnson. 1987. Graphical estimation of sky-view factors in urban environments. Journal of Climatology, 7, 193-197.

Wiki, A., Vogt, R., Parlow, E., \& Petrescu, F., 2015. Analysis and modelling of meso- and micro-scale urban climate in Bucharest, Romania. ICUC9 - 9th International Conference on
Urban Climate jointly with 12th Symposium on the Urban Environment, 20-24 July 2015, Toulouse, France

Revised August 2016 